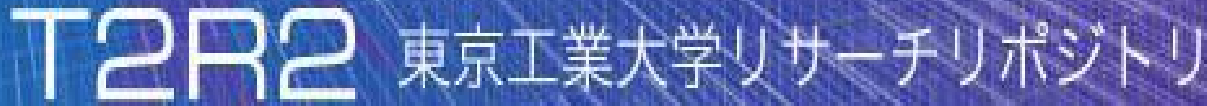

\section{Tokyo Tech Research Repository}

\section{論文 /著書情報 \\ Article /Book Information}

\begin{tabular}{|c|c|}
\hline Title & $\begin{array}{l}\text { Analysis of the Matching between Customer Needs and Patent } \\
\text { Application Portfolio about Unmanned Aerial }\end{array}$ \\
\hline Author & Yosuke Towata, Yoshitoshi Tanaka \\
\hline Journal/Book name & $\begin{array}{l}\text { Portland International Center for Management of Engineering and } \\
\text { Technology (PICMET) } 2016 \text { Proceeding, , , , pp. 1619-1629 }\end{array}$ \\
\hline Issue date & 2016, 9 \\
\hline DOI & https://doi.org/10.1109/PICMET .2016.7806801 \\
\hline URL & http://www.ieee.org/ndex.html \\
\hline Copyright & $\begin{array}{l}\text { (c) } 2016 \text { IEEE. Personal use of this material is permitted. Permission } \\
\text { from IEEE must be obtained for all other users, including } \\
\text { reprinting/republishing this material for advertising or promotional } \\
\text { purposes, creating new collective works for resale or redistribution to } \\
\text { servers or lists, or reuse of any copyrighted components of this work in } \\
\text { other works. }\end{array}$ \\
\hline Note & $\begin{array}{l}\text { このファイルは著者 (最終) 版です。 } \\
\text { This file is author (final) version. }\end{array}$ \\
\hline
\end{tabular}




\title{
Analysis of the matching between customer needs and patent application portfolio about Unmanned Aerial
}

\author{
Yosuke Towata *, Yoshitoshi Tanaka \\ Graduate School of Innovation Management \\ Tokyo Institute of Technology, Japan \\ * = Corresponding author
}

\begin{abstract}
In recent years, UAV called "Drone" has been getting popular, and more opportunities to be reported. Also it becomes easily available for the consumers, and the deployment of various industrial applications are expected. On the other hand, the legal regulation is requested to be more strict to avoid accidents and problems occurred by technical aspects. Companies can acquire the patent rights by the results of development. However, they are often conducted by techniques aspects without considering customers' needs. In some cases, patent portfolio does not meet meets the customer needs. Exclusive rights with weak customer needs do not contribute to increase the market share, the portfolio matching with customers' needs are essentially expected by the company. Therefore, we analyzed for matching between the patent portfolio and customer needs of the UAV manufacturing companies. So, we focus on the regulation and its practical data to grasp the customers' needs, analyzed for matching between the patent portfolio and customer needs of the UAV manufacturing companies.
\end{abstract}

\section{Introduction}

Multirotor type UAV called "drone" (unmanned aircraft) has been attracting attention. In 2013, Amazon has announced a package delivery service, "Prime Air" using the UAV. If the video is published, in all the world, expectations for the industrial use of the UAV has increased at a stretch. Similarly, the transport company leading DHL of Germany, from 2013, to take advantage of the UAV, was to start the delivery project called "DHL parcelcopter". In September, 2015, the first round of international conference InterDrone is performed in Las Vegas, lectures by 3D Robotics of CEO Chris Anderson has been carried out. Chris Anderson, "the definition of the drone, the Internet, the device has evolved to include the cloud", "now drone, from" aircraft without a pilot ", is changing to" smartphone with a propeller "'" and Stated. In other words, UAV is connected to the network future, suggesting that a variety of role.

In 2010, in CES2010 was held in Las Vegas, Parrot has announced a multi-Copter type UAV "AR.drone" that can be operated in communication from the iPhone. Anyone can 
enjoy the easy Aerial and intuitive operation. The packaged product can say the world's first, is a commercial multirotor type UAV consumer AR. Drone is praise, was awarded the 2010 CES Innovation Award, Parrot has become a pioneer of commercial UAV.

\section{Definition of multirotor type commercial}

\section{II.1 Classification of UAV}

UAV, as described above, the common point that "not a human being riding." Otherwise, a concept including a variety of types of aircraft. They can be further classified form of wings is flying principle used during take-off, type and method of supplying power, or self-supporting flight possible or human operated, the size of the aircraft, by the function of such. And, these functions are considered to be selected depending on the application.

\section{II.2 The difference of the fixed-wing aircraft and rotorcraft}

Fixed-wing aircraft is generally a structure having two wing having the same structure as such airline passenger plane, it is necessary to horizontally sliding in order to obtain the necessary lift for takeoff. Although it is not possible when you take off the fixed-point waiting early movement in the horizontal direction. It is efficient in time or fuel basis with respect to movement in the horizontal direction. Exceptionally, in the military, there is a VTOL machine such as known as "Osprey", is it possible to horizontal flight by the vertical take-off and the main wing by the rotating blades.

On the other hand in a rotary wing aircraft do not require a runway, can be vertical take-off, it can be fixed point waiting by hovering. That amount, the movement in the horizontal direction efficiency is poor, flight speed cannot be increased as fixed-wing aircraft.

\section{II.3 Features of the single-rotor type}

Single rotor type motor is located in the structure has been recognized as a so-called helicopter conventionally. And basically, it is to fly by a single propeller (rotor). Reversal torque is generated by the rotation of the main rotor is in the air. Therefore, general helicopter is provided with a tail rotor to offset this. In addition, there is also such a tandem rotor type and coaxial type, in principle, is of variable pitch, which will be described below, are those similar to the single-rotor type. Single rotor-type characteristic is that which changes the pitch of the propeller during rotation. Variable pitch is a technique has also been utilized, such as a propeller and ships screw of fixed-wing aircraft, and determines the movement direction in the air by changing the 
machine control pitch. Single-rotor machine of variable pitch to do so, take a fairly complex mechanism and its control, such as a swash plate. Helicopter of the conventional single-rotor type is the same.

\section{II.3.1Technical characteristics of UAV}

Multirotor type characteristics, when compared to single-rotor type, and that the number of rotors is plural, is that the propeller pitch is fixed. The number of rotor have a even number to offset basically 4,6,8 $\ldots$ and reversing torque, movement in the front and rear left and right is controlled by varying the rotational speed of each rotor individually. Therefore, necessary to change the propeller pitch without complex mechanical control and mechanism is not required. So to speak, in a multi-Copter type, may be said to machine control other than the rotation speed of the propeller is nil. This point is the greatest feature of the multirotor type UAV called recently drone. As a result, by replacing the mechanical design problems programming problem, it has become the posture stability significantly improves, and can be inexpensively realized.

For the rotational speed of the propeller, on the basis of the instructions and information of the sensor from the operation equipment, flight controller to control. Therefore, what is important for the stability flight control is the type and the performance of the sensor and program for flight control,. To general consumers to own a multi-Copter type UAV, it is sufficient to purchase a commercial flight controller to suit the required frame and motor, the propeller. The flight controller, an acceleration sensor with miniaturization, a gyro sensor, a magnetic sensor, such as pressure sensors are already included. Such flight background controller is realized at low cost, miniaturization of the mobile phone and sophistication are mentioned as the reason. Such as the modern smartphone is equipped with various sensors, the supply of small-sized high-performance sensors from companies to UAV manufacturer of sensor has become possible.

\section{II.3.2 Definition of Commercial Use UAV}

From the above, a multi-Copter type commercial UAV to be the subject of investigation in this project report,

(1) People cannot ride from its structure

(2) Intended to be sold as a consumer not for military

(3) Having a plurality of rotary wing does not have a fixed wing

(4) Multirotor type of fixed pitch rather than a single-rotor type of variable pitch

To target more of the four conditions are met unmanned aircraft. 


\section{Relations between R\&D and Customers' Needs}

\section{III.1 R\&D Information extracted from Patent Information}

The results of technology development by companies, come to fruition as the sole and exclusive based on the patent rights by the patent application activities. Especially in the new industries, similar products by imitation becomes difficult and differentiation hit the market, a result that fell in price competition, investment in technology development becomes difficult recovery. Therefore, in general, for the technology that features its own developed, do the patent application activity, to acquire the sole and exclusive for the patented invention by acquiring the patent rights. Information obtained from patent information There are two broadly divided into, and rights information indicating whether legally who have any such rights, is a technology information that shows who is what invention. In this project report, to extract or commercial UAV manufacturers from patent information is doing what technology development.

\section{III.2 Customers' Need on Commercial Use UAV}

1. Declared needs (for example, a customer wants a cheap car)

2. Real needs (for example, the customer, rather than the purchase cost, wants a cheap car of maintenance costs)

3. Needs that are not declared (for example, the customer, are expecting good service from the dealer)

4. Joy needs (for example, the customer wants to be the dealer us with a car navigation system)

5. Hidden needs (for example, a customer, it is to think that you have a good shopping to friends)

Thus, the demand includes those not actually declared, if there is no still product the needs would that there is no means to satisfy it while there is a need state.

In addition, according to the Umezawa, consumers will not say that I want things not now, when it is presented that there is a nature to be aware of it. In order to spawn a new market by innovative product is going to have to understand the strong needs of unmet that potential in the consumer's mind.

Multirotor type UAV is not had products in the commercial market so far. The recent spread rapidly in the background, presumably because there was elements and applications to meet any needs that have not been manifest. December 10, 2015 and later, in Japan to fly the more UAV 200g, it has become necessary to be an objective of 
the hobby get an application to allow the Ministry of Land, Infrastructure and Transport. Multirotor type or UAV something like what needs to be considered that is satisfiable, from the description of the application according to the contents of the application is considered to be guess the purpose of the flight.

\section{Purpose of this Research}

After revision of the Aviation Law, knowing whether multirotor type UAV is in use by any application is important to consider the future industrial use. In this project report, by analyzing the patent information of the major companies to provide a multi-Copter type UAV, to understand whether there have been technological development with an emphasis on any field. In addition, to investigate the practical applications of multirotor type UAV, multirotor type UAV guess about the needs to be met. On top of that, by comparing the technology and the use of multi-Copter type UAV, consider the use of the technology in order to satisfy the needs. In addition, in light also situation of laws and regulations, and needs that might be occurring in the future, consider the expected function in UAV necessary in order to achieve it.

\section{Big 3 Companies for Commercial Use of UAV}

(1) Parrot

Parrot is a French company that was founded by Henri Seydoux in 1994, car automotive communications equipment, sells audio equipment. In 2010, it announced the AR.Drone to maneuver via Wi-Fi from smartphones, as described above. Then, in 2012 AR.Drone 2.0, in 2015 announced the Bebop Drone, began selling. In 2016 it announced the Disco is a fixed wing UAV to be a company's first in CES2016.

In addition, it has been released and Minidrone an ultra-small multirotor type UAV, a remote-operated vehicle model Jamping Sumo jump has two wheels.

(2) DJI

DJI is a company that is Frank Wang Tao that was studying the attitude stabilization technology of the single-rotor helicopter while attending the Hong Kong University of Science and Technology was founded, the official name Shenzhen Da-Jiang Innovations Science and Technology Co., called Ltd.. Phantom Series DJI was launched from 2012, is the most sold UAV in the world, the company since 2013, is said to account for more than $70 \%$ of the global market share in sales.

(3) 3D Robotics 
CEO of 3D Robotics is known in the book, such as MAKERS, is the editor-in-chief Chris Anderson of the original WIRED. Had originally it operates a DIY DRONES is a community where people gather who are interested in self-made drone, has led to cause the company for UAV development. In September 2014, it started selling the IRIS + . IRIS + is a UAV designed for hobby purposes, may be the aerial by mounting the GoPro model of camera. In addition, not only the airplane body, has published a flight control application Droid Planner Series Tower of open source, is realized the autopilot function. In May 2015, it has started selling the SOLO drone in the United States. This aircraft is not only consumers are directed to aerial photography market of professional skill in the art. Aerial for the camera is using a made of GoPro.

\section{Results of Patent Information Analysis}

\section{V.1 Patent applications by Parrot}

\section{V.1.1 Number of patent application at the first country}

The number of patent applications in France is the first country of the Parrot is shown in Figure 1. Parrot is a 2010 start the application on the UAV since 2006, the number is most often are announced the AR.Drone at CES. Then it is also carried out the application by several cases in a year. 2015 content is still unpublished.

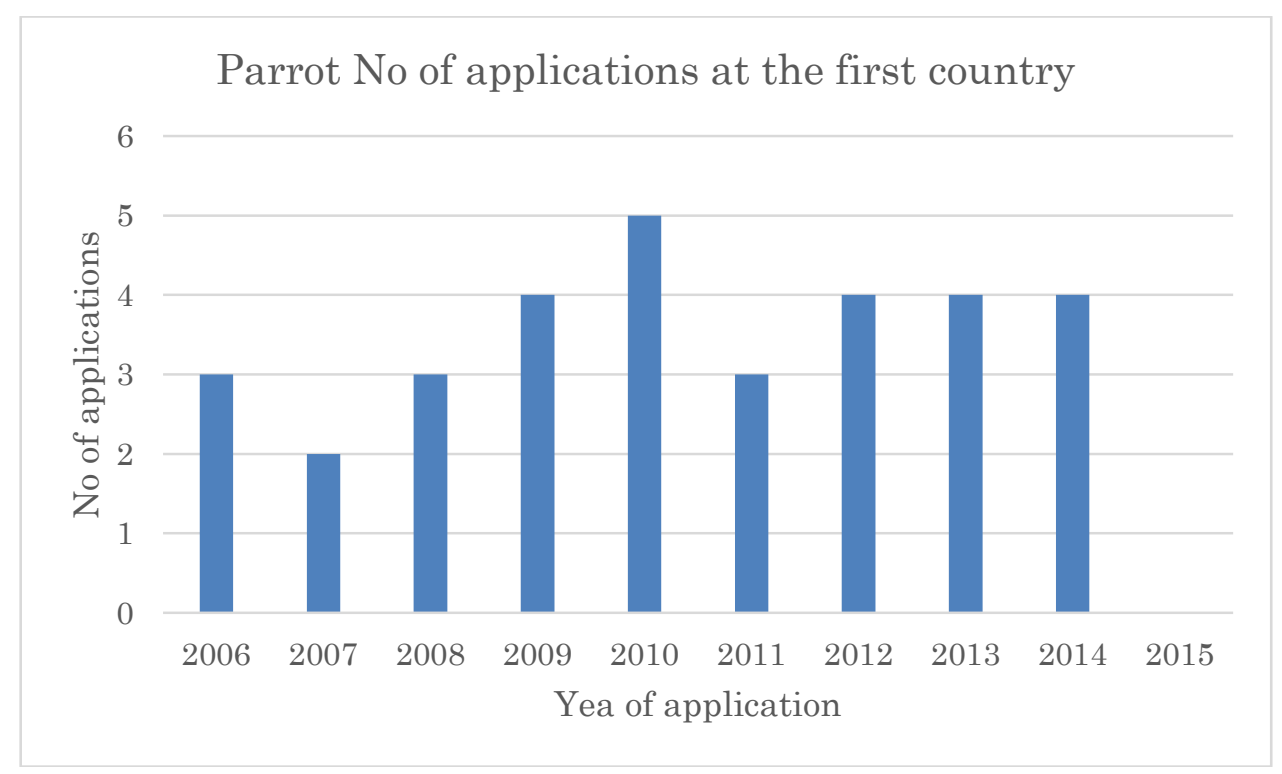

Figure 1 Parrot/ No of patent applications at the first country, Data from JP-NET

The number of applications in the first country by Parrot is small, but Parrot is very active for foreign patent applications with priority declaration. The number of family 
patent applications in other countries is described in Table 1.

Table1 No of foreign patent applications by Parrot

\begin{tabular}{|l|c|}
\hline AT & 2 \\
\hline CN & 22 \\
\hline DE & 12 \\
\hline EP & 28 \\
\hline HK & 3 \\
\hline JP & 26 \\
\hline US & 27 \\
\hline WO & 12 \\
\hline Foreign Ratio & $91 \%$ \\
\hline
\end{tabular}

Data from JP-NET

While the first country application is a total of 32 , the fact that the number of family literature is 134 is that there is a foreign application of more than 4 with respect to the first national application of 1 , foreign application It said to be active against. Of course, it is also PCT application is included as a count, PCT ratio as in the above table is small. What many in the application country that you are targeted, Japan, Europe, the United States, there is in China, it is considered that to choose the country in which there is a lot of 5-pole Patent Office of the application rather than a market countries. Application to Japan is also a positive, suggesting that Japan of the UAV market is in the field of view.

\section{V.1.2 Analysis on technical characteristics from patent classifications}

The IPC and CPC granted to the applicant of Parrot, are arranged in order from a lot of the grant number, to grasp the technical contents are the focus application.

Usually, if you want to guess, such as the quality of the technology by using the patent information is, of registration that has passed through the examination existence and, often items such as the number of citations is referenced, of grant Number of time-series also for IPC Although in many cases to see change, etc., in the patent application network of this extracted companies, application that there is not much factors such as changes in the relatively new technology time that has been started, progress because there are a lot of invention that examination has not been completed from the fact that patent evaluation, such as gender has not been determined, it was decided to understand the emphasis of the technical content by the distribution of IPC. Those positioned above the IPC granted to the applicant of Parrot is shown below in 
Table 2.

Table 2 IPC given to patent applications by Parrot

\begin{tabular}{|l|r|l|}
\hline IPC & No given & Overview of technology \\
\hline A63H 27/133 & 17 & Helicopter as a toy airplane \\
\hline A63H 30/04 & 16 & Handling of toys by the wireless communication \\
\hline G05Q 1/08 & 10 & Attitude control \\
\hline A63H 27/127 & 7 & Toy airplanes that are enabled vertical take-off \\
\hline G08C 17/02 & 7 & Maneuvering by wave communication \\
\hline B64C 39/02 & 6 & Aircraft that features a special purpose \\
\hline A63H 27/24 & 3 & Toy airplane with battery as power \\
\hline
\end{tabular}

Data from JP-NET

Looking at this result, the application of Parrot, it can be seen that the invention was regarded as "model airplane" is large. Invention belonging to $\mathrm{A} 63 \mathrm{H}$ is intended to be essentially classified in model airplanes. Further, A63H 30/04, G08C 17/02 is a technique for maneuvering the aircraft by using a radio wave. G05Q 1/08 is related to control in order to stabilize the posture. What can be said from these distributions, except premise that helicopter conventionally is one that controls the aircraft by a radio, a characteristic portion in the application of Parrot are for stabilizing the posture which belongs to G05Q 1/08 it is considered to be a technique related to the control.

Also, it is shown in Table 3 for the CPC.

Table 3 CPC given to patent applications by Parrot

\begin{tabular}{|l|r|l|}
\hline CPC & CPC given & Overview of technology \\
\hline A63H 27/12 & 36 & Classification of the toy airplane \\
\hline A63H 30/04 & 21 & Handling of toys by the wireless communication \\
\hline B64C 39/024 & 13 & Aircraft to steer by radio wave \\
\hline B64C 2201/108 & 9 & UAV using a rotating blade \\
\hline B64C 2201/027 & 8 & UAV flight frame (Flying tops) \\
\hline A63F2300/69 & 7 & $\begin{array}{l}\text { Those that bring the elements of the real world to } \\
\text { the world of the game }\end{array}$ \\
\hline G08C17/02 & 7 & Maneuvering by wave communication \\
\hline A63F2300/8017 & 7 & $\begin{array}{l}\text { Which is characterized by the kind of game (flight, } \\
\text { onshore and underwater) }\end{array}$ \\
\hline
\end{tabular}

Data from JP-NET

Distribution of the CPC, a large difference is not have followed the basic IPC of 
distribution, clearly classification B64C 2201/108 that it is UAV has been newly extracted. Others include, A63F 2300/69, such as A63F 2300/8017, that classification has been granted on the game has been extracted.

Applicants for these games, on the screen of the tablet terminal to be used as a maneuvering unit, were things like make a shooting game in the UAV each other reflects the image of the reality of the aircraft.

Is the initial application, AR that has been announced as the "AR.Drone" at CES2010: was something good to say that is a (Augmented Reality augmented reality) technology itself.

\section{V.1.3 Important inventions based on the no of patent family}

Upon identifying the important invention for the Parrot, using an evaluation by foreign family number of documents. Since The largest percentage in the patent application cost is the translation fee, the fact that the application to a large number of countries, it comes to invention that companies are multiplied by the expectations.

Table 4 application of family literature highest number in Parrot in, and shows the patent number of the case where there is a corresponding patent, the outline of the invention of the check the description of the specification. There are steering and the video display function using a tablet terminal as a feature of the Parrot, by tilting the tablet, the invention has come out on top of being able to steer the UAV. The specification of the application relating to maneuver the UAV with tablet terminals typified in this application, it has been cited as a problem which can be intuitive and focused on pilot operations experience.

There was also a vertical takeoff control technique that analyzes the image vertically downward to detect the altitude and aircraft increases during the vertical takeoff. This is, or to be able to perform also easily fly by inexperienced person to maneuver, solves the problem that a child can flight control independently of the GPS even when to fly indoors. While there is also such a information processing technology, housing and the aircraft in order to protect the sensor unit from vibration, mechanical design technology also emphasis has been placed, such as the exchange is easy structure of the propeller and motor.

Overall can be said about the application of the Parrot is that human beings have to maneuver the UAV is an emphasis on technology to enjoy the experience of flying.

Further, the application registered patents in the first country have been made many, is presumed to have a high technical terms UAV. 
Table 4 Parrot's patent applications as top no of family

\begin{tabular}{|l|l|l|r|}
\hline Overview & $\begin{array}{l}\text { FR } \\
\text { Patent } \\
\text { application } \\
\text { no }\end{array}$ & $\begin{array}{l}\text { FR } \\
\text { Patent no }\end{array}$ & $\begin{array}{l}\text { No of } \\
\text { family }\end{array}$ \\
\hline $\begin{array}{l}\text { Due to the inclination detection of the tablet } \\
\text { Operation of the aircraft }\end{array}$ & 200806665 & & 8 \\
\hline Virtual shooting game & 200806800 & 2939325 & 7 \\
\hline Operation of the aircraft by the tablet & 201051751 & 2957265 & 7 \\
\hline Fuselage of the housing & 200958011 & 2952787 & 6 \\
\hline $\begin{array}{l}\text { Consolidated structure of exchange easy motor and } \\
\text { propeller }\end{array}$ & 200958013 & 2952549 & 6 \\
\hline Vertical take-off control by the vertical image analysis & 201054945 & 2961601 & 6 \\
\hline
\end{tabular}

Data from JP-NET

\section{V.2 Patent applications by DJI}

\section{V.2.1 Number of patent application at the first country}

The number of patent applications across at China first country of DJI shown in Figure 2. Starts application from DJI In 2009, the number is the most common is the 2014 after the Phantom series was released. It is also published for 2015 minutes, trying to eliminate the other companies filed voluntarily published claims. In addition, Table 5 shows the breakdown of the foreign application family application country of DJI.

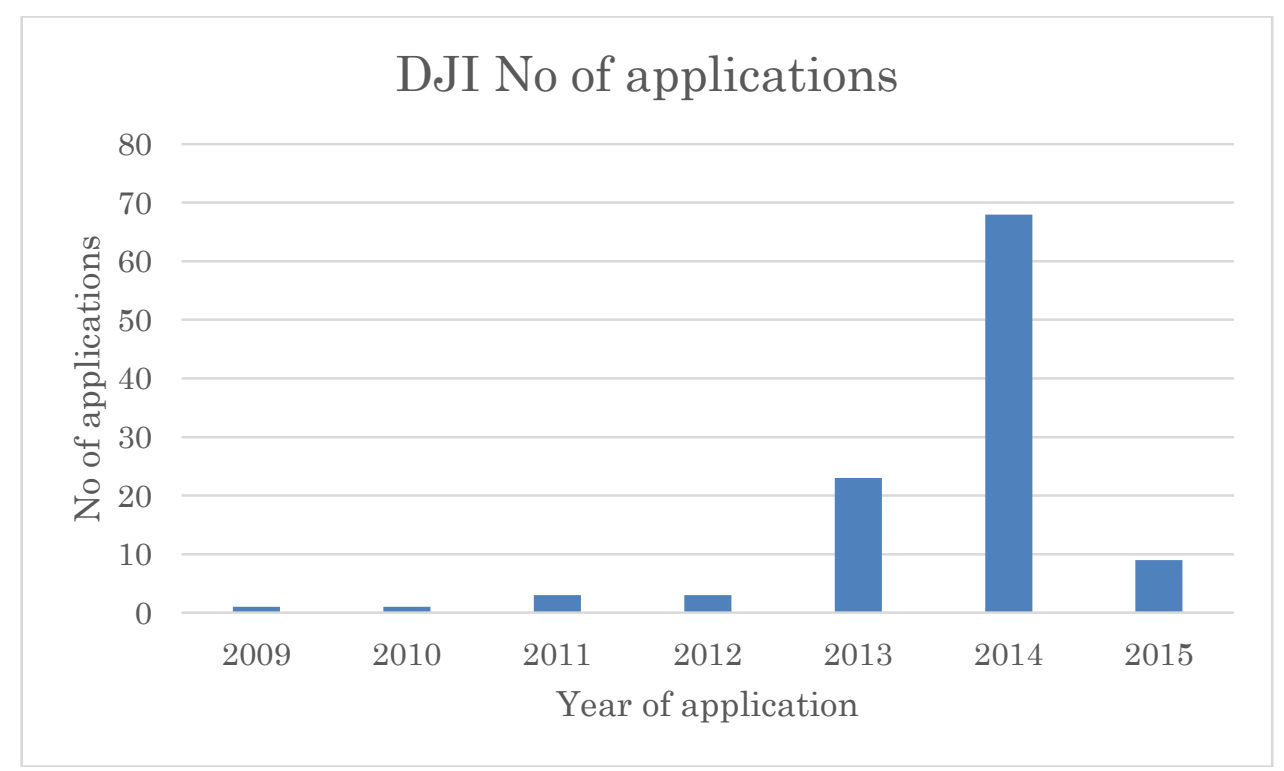

Data from JP-NET 
Figure 2 DJI/ No of patent applications at the first country, Data from JP-NET

Table5 No of foreign patent applications by DJI

\begin{tabular}{|l|r|}
\hline AU & 2 \\
\hline $\mathrm{CA}$ & 2 \\
\hline $\mathrm{DE}$ & 1 \\
\hline $\mathrm{EP}$ & 10 \\
\hline $\mathrm{IN}$ & 1 \\
\hline $\mathrm{JP}$ & 5 \\
\hline $\mathrm{KR}$ & 2 \\
\hline $\mathrm{MX}$ & 2 \\
\hline $\mathrm{RU}$ & 2 \\
\hline TW & 3 \\
\hline US & 19 \\
\hline WO & 35 \\
\hline Foreign ratio & $35 \%$ \\
\hline
\end{tabular}

Data from JP-NET

DJI is, it can be seen that in the foreign application countries that have an emphasis on the United States and Europe. Applicants for Japan is 5 and less at the moment. However, a large part of the recent application, is likely to increase by the national phase of the PCT application.

\section{V.2.2 Analysis on technical characteristics from patent classifications}

About IPC and CPC that has been given to the application of the DJI, show those located in the upper level for the grant number in Table 6 below.

Table 6 IPC given to patent applications by DJI

\begin{tabular}{|lr|r|l|}
\hline IPC & IPC given & Overview \\
\hline F16M & $11 / 18$ & 11 & Support means for relatively moving the article \\
\hline F16M & $11 / 06$ & 9 & Supporting means of the rotatable article \\
\hline G05D & $1 / 10$ & 9 & Control of the course in the three-dimensional \\
\hline B64D & $47 / 08$ & 6 & Placement of the camera \\
\hline G03B & $17 / 56$ & 6 & The camera of the holder \\
\hline B64C & $27 / 32$ & 4 & Aircraft using a rotating blade \\
\hline
\end{tabular}




\begin{tabular}{|ll|l|l|} 
F16M & $11 / 12$ & 4 & Two or more axes of rotation retainer \\
\hline F16M & $11 / 16$ & 4 & Holder has the effect of fixed \\
\hline
\end{tabular}

Data from JP-NET

Looking at this result, it can be seen that there are many invention relates to the holding of the camera in the application of DJI. F16M $11 / *$ to belong invention relates to application on the gimbal are all camera of the holder. In addition, also the section B64D 47/08, G03B 17/56 is a different, but the invention of the camera around. What can be said from these distributions, characteristic portion in application DJI is said to be an invention relating to the holding of the camera. Further, it is shown in Table 7 for the CPC.

Table 7 CPC given to patent applications by DJI

\begin{tabular}{|l|r|l|}
\hline CPC & CPC given & Overview \\
\hline B64C 39/024 & 7 & Aircraft to steer by radio \\
\hline B64D 47/08 & 7 & Placement of the camera \\
\hline B64C2201/027 & 6 & UAV flight frame (Flying tops) \\
\hline B64C2201/127 & 6 & UAV to be used in the Aerial \\
\hline B64C2201/108 & 5 & UAV using a rotating blade \\
\hline A63H 27/02 & 4 & Model airplane \\
\hline F16M 11/06 & 4 & Supporting means of the rotatable article \\
\hline F16M 11/18 & 4 & Support means for relatively moving the article \\
\hline
\end{tabular}

Data from JP-NET

DJI is granted number of CPC is small because fewer foreign application, it can be seen that in many cases invention relates holder of the camera as in the IPC.

\section{V.2.3 Important inventions based on the no of patent family}

Table 8 shows the application number of family literature highest number in the DJI, the outline of the invention of the check the description of the specification. For in using the composite priority DJI is doing a complex foreign application, not life-support that one application one invention.

Application Family Reference number higher are both relate the structure of the three-axis camera gimbals for holding the camera, it is for stable Aerial movie shooting. The operation of the gimbal is to be done based on the sensor information from the 
inertial module has filed a housing of the inertial module relates to an electric control method of operating a gimbal in motor.

Furthermore, there are applications for the communication method for operating in cooperation leaving the single UAV and the photographer and the operator. This is one the one hand the imaging is a technique for concentrate on steering.

Then, raising the droop has been supporting leg at the time of landing after take-off, it was also filed on the mechanism for widening the field of view of the camera Thus, true for the entire application of DJI from these results is that has been developed a technique for implementing the UAV specializing in aerial.

Table 8 DJI's patent applications as top no of family

\begin{tabular}{|c|c|c|}
\hline Overview & $\begin{array}{l}\text { CH Patent } \\
\text { application no }\end{array}$ & $\begin{array}{l}\text { No of } \\
\text { family }\end{array}$ \\
\hline \multirow{3}{*}{ 3-axis camera gimbal structure } & 201110380344 & \multirow{3}{*}{26} \\
\hline & 201110380351 & \\
\hline & 201410182852 & \\
\hline \multirow{5}{*}{ 3-axis camera gimbal structure } & 201310109643 & \multirow{5}{*}{10} \\
\hline & 201310109693 & \\
\hline & 201310109706 & \\
\hline & 201310109707 & \\
\hline & 201310432300 & \\
\hline Housing of the inertial module & 201080068428 & 7 \\
\hline 3-axis gimbal electric control method & 201310330321 & 6 \\
\hline \multirow{2}{*}{ Radio-controlled by two of the steering machine } & 201310468739 & \multirow{2}{*}{5} \\
\hline & 201480002508 & \\
\hline \multirow{2}{*}{ Deformation mechanism of the support leg } & 201310008317 & \multirow{2}{*}{5} \\
\hline & 201380048477 & \\
\hline
\end{tabular}

Data from JP-NET

\section{Analysis from the approved application form}

For permission and approval in accordance with the flight of the unmanned aircraft, at the Ministry of Land, Infrastructure and Transport of the site, part of what has been the 
permission and approval has been posted. At the time of the January 16, 2015, application of 51112 were received, 469 have been authorized and approved. Have been published as of which 231 Reviews has been granted and approved [27].

What is published, the applicant, the applicant terms on the Aviation Law, flight date and time of flight location, name of the aircraft, of the permit approval number, in the authorized date of approval. Applicants from these information, application terms, the analysis for the name of the body do.

Analysis of the application terms

A permit or approved application terms shown in Figure 3. First of all, the flight of the "population concentration district" in the application of the provisions of Article 132 (flight location) was the 178 of the most 231 Reviews. This is due to the fact that most cities portion corresponds to the population concentration area.

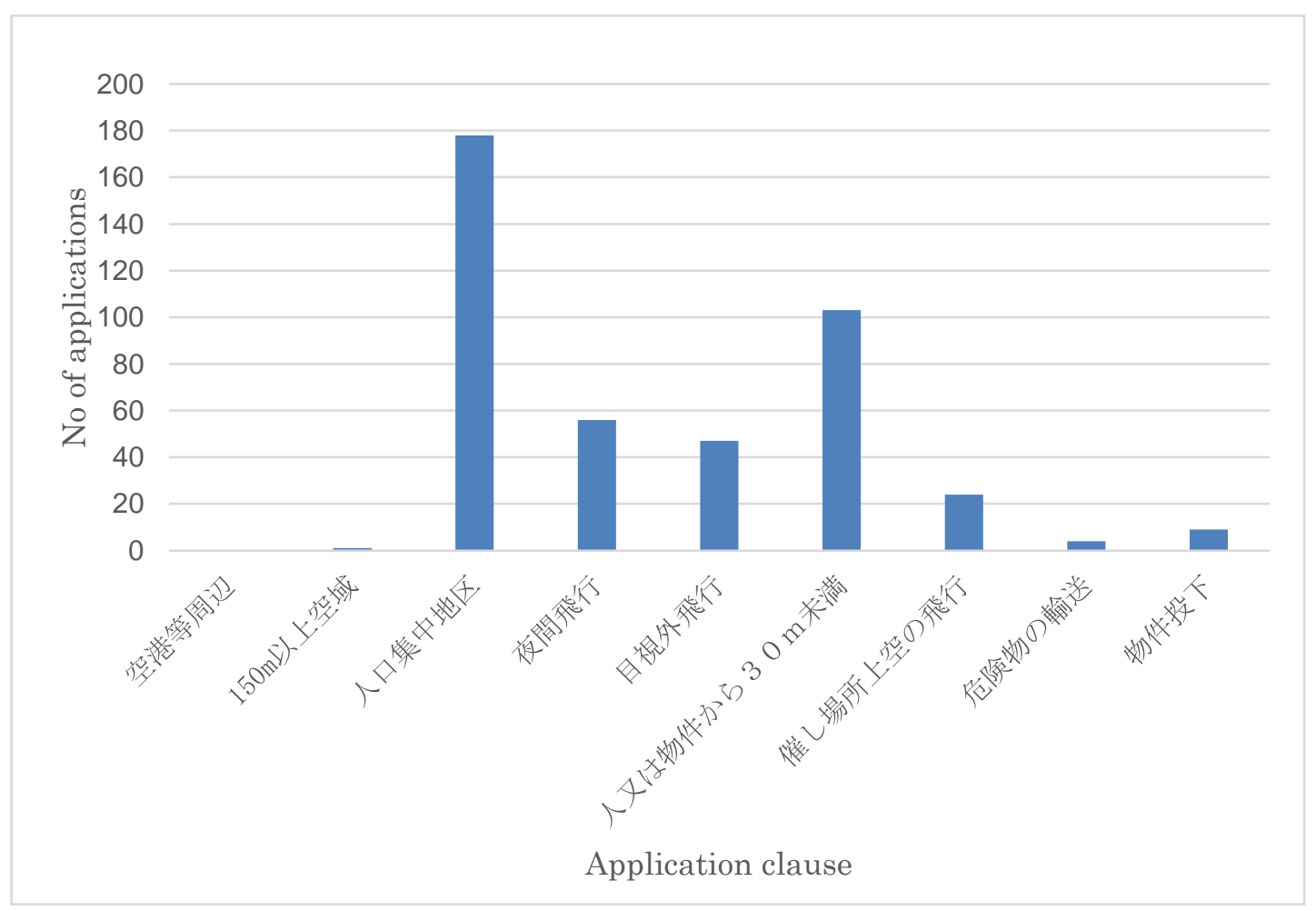

Figure 3 Number of applications of each application clause

The applicant and flight research about the purpose of

Since the purpose of the application is in the Ministry of Land, Infrastructure and Transport for personal information was that not the public, based on the above results, perform a search on the Internet separately from the name of the received applicant's 
permission and approval, the individual with to identify the applicant, except, it was examined for the purpose of the flight. The day the search was conducted is a 7 to 15 January 2016.

For the purposes of items of the flight, in light of the standard purpose of the flight, and a description of the table for the specific example of the "examination procedure of authorization and approval on the flight of the unmanned aircraft," according to the Ministry of Land, Infrastructure and Transport, has been identified on the basis of clearly stated business content to the applicant's home page of the business content such as page of, to extract those that conform to the purpose of each flight. The results are shown in Figure 4 below.

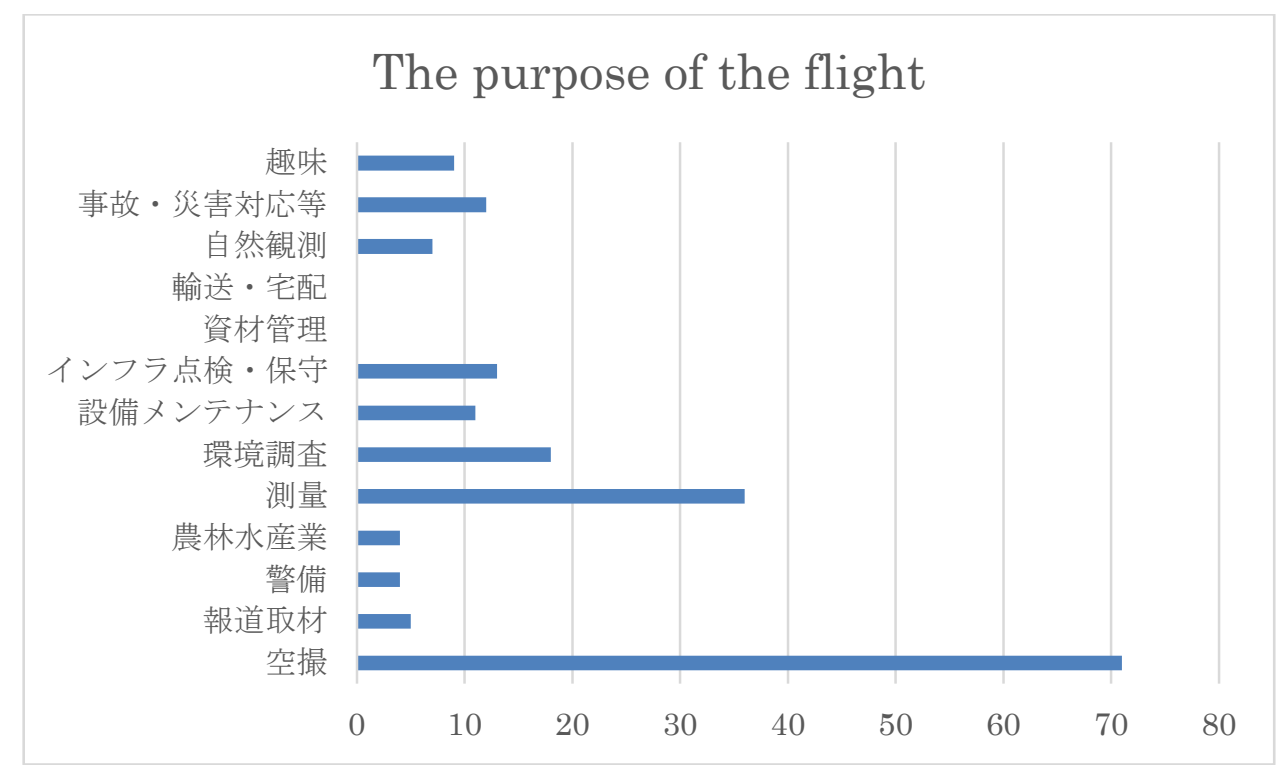

Figure 4 The purpose of the flight of the UAV

In the results of the investigation, the applicant for the purpose of "Aerial" was the most common. The "Aerial", as described in the table above, shooting of landscape and facilities, TV · filmmaking, in which an event such as photographing. That is, to obtain a video or photo performs taken from a camera attached to the UAV.

Then often it was is given to the applicant for the purpose of "surveying". The "survey", there is a survey or the like in the construction site. For this, there is no direct surveying function to UAV itself, on the basis of the image data obtained, the vertical downward aerial ortho-mosaic processing and to planar map of bonded photographic images, from multiple angles by integrating photographic images from the angle it is 
conceivable to perform 3D modeling of terrain. Therefore, it is considered to be the purpose of the indirect measurement based on the data acquired using a UAV.

For the "Environmental Research", "equipment maintenance", "infrastructure inspection and maintenance" is, the applicant to be carried out as a business to any there were many. For "Environmental Survey" is a human example to confirm the situation She sees the sky, and the like by the UAV and situation of easily Tachiire not the location of the soil and the banks of the pollution. For the "equipment maintenance", "infrastructure inspection and maintenance" is, dirt and check of solar panels, bridges, state of the structure of the tunnel and the like, such as the situation of deterioration of the building, high altitude and the human can not be easily observed, inspection about what is the area of the place are many time-consuming, examples can be cited, such as to check the situation She sees the sky by UAV.

In the "accidents and disaster response", the number is small, but and on-site verification of traffic accident, company to perform the appraisal, include the example used, such as in an accident investigation insurance company.

Examples such as "transportation courier" and "asset management" could not be found. For the drop of transport and property of hazardous materials, at the moment, as described above are recorded in the line item of "agriculture, forestry and fisheries" in the single rotor-type unmanned helicopter it has been limited to approval, their purpose. The "Material Management", which appears to be assumed materials management or the like in the outdoors, the majority of the material is considered to be managed indoors. Since the well flight indoors is not a subject to regulation, because there is no need to obtain permission and approval by the application even in such as in a warehouse doing autonomous flight for check stock, and those not apply at the moment Conceivable.

From the above results, since the constant tendency for the applicant on the basis of the flight object of was observed, Figure 5 shows a summary for each business category. The most common is, video production skill in the art to which corresponds to the purpose of the above Aerial, a Aerial skilled in the art. Are these vendors are doing a service to provide a video doing the Aerial, is doing a service to produce a video and program by processing the sky Transfer video.

Thing that was then a lot is, construction industry, a construction consultancy. These vendors have done a survey and environmental survey to accompany it for construction. 
In addition, it has also carried out inspections and maintenance, etc. of the building. Also, in order to visually grasp the progress of the construction work is like are using the Aerial.

For the other, research and development companies, and at the university seems to be flying for the test. In addition, and that can not be identified applicant's site in part on the Internet, there was a thing is unknown specific can be purpose and application.

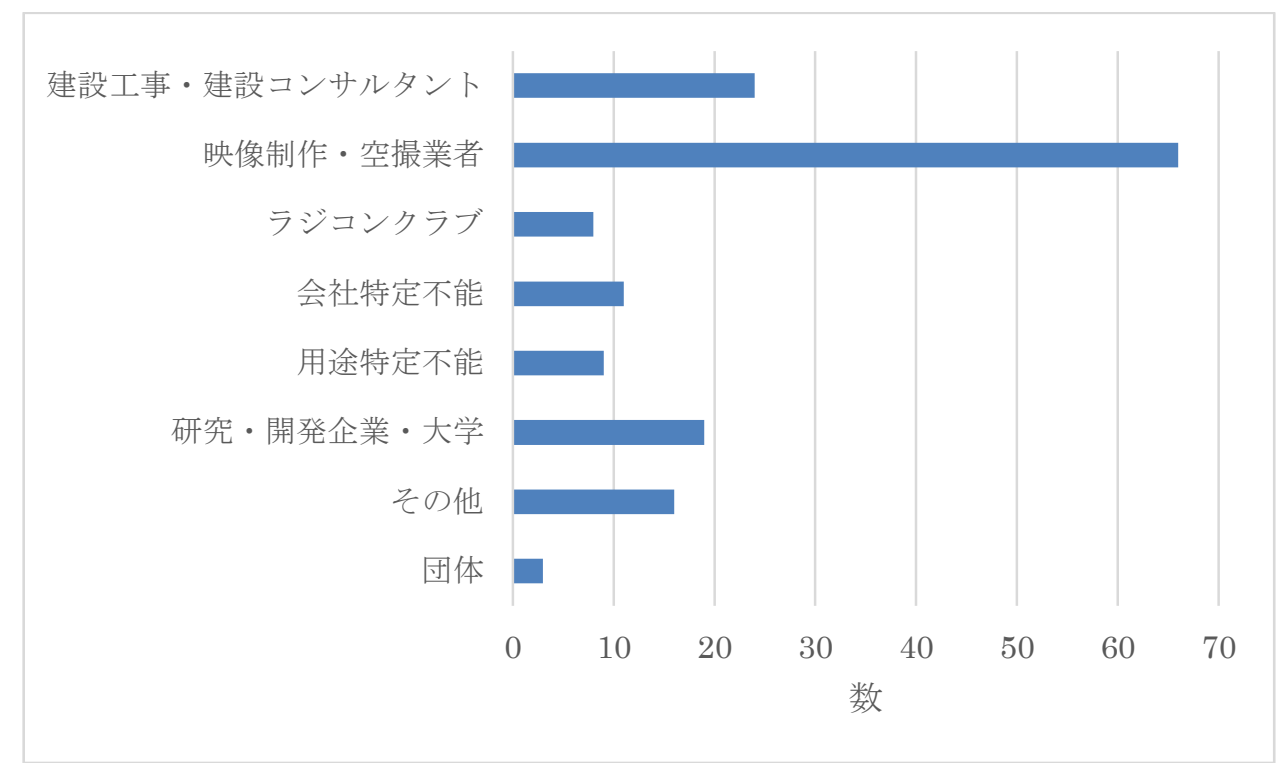

Figure 5 The applicant's business category

From the above results, the majority of those who have received the permission and approval of the flight of the unmanned aircraft, it was found that the aerial skill in the art, and are construction related art.

And more easily put together, most of the persons using the fuselage of the DJI, considered Aerial suppliers and individuals perform aerial, construction relationship skilled in the actual situation is that have a grasp of the surveying and construction situation It is. 


\section{Comparison matching of patent information and the approval application contents}

Compliance with patent application network and the required functions to the UAV Here, technology related to the method of the special flight pertaining to the permission and approval of unmanned aircraft, and for the patent application relating to it to consider. Than the examination procedure "according to the authorization and approval of unmanned aircraft by the Ministry of Land, Infrastructure and Transport, necessary in the case to take a special flight method according to the 2 each issue of 132 Article, meet the" additional criteria in accordance with the flight form. "[30] There is a need. Item This additional criteria, matters relating to the performance and function of (1) aircraft, matters related to maneuvering ability to be imposed on the (2) operator, there are matters concerning the system to ensure the safety (3), imposed as a function of (1) aircraft from this It was extracted for. The basic performance of the speed of the aircraft is largely dependent on the performance of the parts such as motors and sensors with respect to functionality imposed additionally in accordance with a special flight forms, regardless of the existing technology, patents This is because the application was believed to express a novel technique performed.

(1) flight in the flight-entertainment over in less than $30 \mathrm{~m}$ from the densely populated district, people or property

A) having a structure to reduce the harm upon contact Listing for aircraft

When i) reception of GPS or the like is no longer function, has its function of holding the position in the air until the return, it can acquire the position information other than by function or GPS, etc. to allow safe automatic landing capability thing

When iii) unforeseen circumstances has occurred, it has a function is not that the aircraft immediately fall

D) to have the function of limiting the airspace to try to fly

(2) night flight

E) that the attitude and direction has a lamp so that you can accurately visibility for aircraft

(3) visual inspection outside the flight

$\mathrm{Ca}$ ) equipped with an autopilot system, it can be monitored state outside the machine body by a camera or the like which is installed in the fuselage.

(4) of the Transport of Dangerous Goods 
That g) equipment that is suitable for the transport of dangerous goods are provided

(5) Property bombing

For viii) aircraft, it is not a mechanism for carelessly dropped the property

For application on the invention which corresponds to more than A-clock, it was further extracted from the first country patent application of DJI and Parrot extracted above. The results are shown in Table 9.

Table 9 Application number that corresponds to the additional criteria

\begin{tabular}{|l|r|r|}
\hline Function & Parrot & \multicolumn{1}{|l|}{ DJI } \\
\hline Harm mitigation & 1 & 0 \\
\hline When incommunicable & 2 & 1 \\
\hline Falling rate reduction & 0 & 3 \\
\hline Flight area limit & 0 & 1 \\
\hline Lamplight & 0 & 0 \\
\hline Automatic pilot & 1 & 1 \\
\hline Hazardous materials transportation & 0 & 0 \\
\hline ク Property dropped & 0 & 0 \\
\hline Total & 4 & 6 \\
\hline
\end{tabular}

Data from JP-NET

The number of patent applications is also corresponding to the additional criteria in any of the companies was less.

In particular, e) night flight at the time of lighting, g) equipment that is suitable for the transport of dangerous goods, h) for the structure that does not inadvertently dropped the property did not have the application. Although provided as functions for lighting believed was not a certain features as to the patent art. In the two items related to transportation of property, as the UAV of DJI is believed that not a performance that can withstand the function of transporting the property at this stage.

The structure to reduce a) harm, there was filed on propeller guard for the purpose of this in Parrot, the DJI did not.

The technique of holding the position of the air at the time of b) GPS or the like can not be received, there has been filed in any of the companies. For example, in DJI it was that to determine the position with reference to the history of the acquired GPS 
information to it.

For information about features that c) the aircraft is immediately so as not to the time of fall, there is application only to DJI, which activates the parachute and, other propeller so that the speed of the fall in the case where one of the propeller is no longer function to recommendations such as those that control, goodness of fit to the item there was a high application.

The ability to limit the airspace to try to d) flight, in DJI, by referring to the information on the no-fly zone based on the GPS information, there has been filed related to the control not to perform the flight to the airspace .

F) For autopilot, it has been filed in the control method for performing automatic navigation by specifying coordinates in any of the companies.

From the above results, there is a application that overall DJI corresponds to the additional criteria, to infer that there is an advantageous situation in the examination of the application.

\section{Consideration}

\section{VIII.1 compliance with the purpose and patent application of flight}

In this project report, multirotor type commercial UAV which is a leading manufacturer Parrot, and analyzes the patent application for DJI, was extracted the characteristics of their respective companies.

According to this, Parrot has been found to be performed and posture control in the air of the aircraft, a technical development with an emphasis on intuitive maneuver of the aircraft. On the other hand DJI was found to have carried out a technical development that specializes in "Aerial" to shoot the video in the air.

In addition, Land, from the results of the contents of the publication of about the flight of unmanned aircraft that has been authorized and approved by the Transport Ministry, the majority of aerial companies that have done as a service, Aerial data construction industry relationships that make the core business skilled in the art, by individuals found to be a flight of hobby, most of which was the application by aircraft of DJI.

From these results, is related to the moment the sky is what is being used as a business in the flight of the UAV in Japan in the shooting, said that aircraft share by DJI that specializes in high-quality aerial photography has been almost exclusively it can be said that is also a situation is not an exaggeration.

Although the factors that aircraft of the DJI is employed a variety of factors such as price and awareness is likely to be related, functions related to Aerial is also believed to 
be the cause, from the patent application content for technology related to its function confirmed.

Therefore, this until the product can not be satisfied, the multirotor type commercial UAV is estimated that the needs could be newly satisfied was that it is possible to perform high quality aerial.

\section{VIII.2 compliance with patent application and the required function to unmanned aircraft}

For the application corresponding to the additional criteria for unmanned aircraft in the examination procedure of the Ministry of Land, Infrastructure and Transport, Parrot, DJI but both sufficient number of applications did not, is fit for the overall contents of the additional criteria of the application by the DJI considered to be high. This is speculated that not became contributes to aircraft DJI is employed.

Transportation or even hazardous materials in any of the company, there is no application adapted for dropping the property, a situation which is not to be realized as a product. This feature currently is believed to have a single rotor-type unmanned helicopter.

\section{What is required for the future of the UAV}

Based on the results of the investigation of this project report, we discuss what is required to multirotor type commercial UAV future.

First, as a technique about the capabilities of the aircraft, to have the ability to comply with additional criteria of unmanned aircraft, may be required from now on that application as compared to the aircraft, such as the existing DJI is facilitated is there. For example, the number in the results of the above study was small, the structure and such as harm to property and people by contact at the time of the aircraft falling is reduced, the aircraft in the night flight posture, such as lights, which can be easily determined it is a function.

In addition, when considered from the aspect of the purpose of the flight, from the time of the results, the purpose of the flight, but he that is Aerial, what you want the original customer to order the shooting in aerial skill in the art is an air of the video, construction is a topographical data in the work relationship of skill in the art. Sky For video shooting skill in the art to shoot, but there is one aspect of creative activity by humans, such as movies and shows, there is no room to be included in such a creative element for geographical data, more mechanical automatic control It is considered to be required. Thus, the purpose is also believed that gradually differentiated as a means of 
satisfying this being enclosed in a common section of Aerial currently. Therefore, motivation to adopt a fuselage that is versatile for each purpose is considered to gradually faded.

In addition, in the other purposes, which is uses for transportation, etc. of small goods of permits and approvals at the moment. It has been recognized that have been developed by Amazon and the like, are those expected realized.

\section{Reference}

[1] G CaiDias, L SeneviratneJ. (2014). A survey of small-scale unmanned aerial vehicles: Recent advances and future development trends. Unmanned Systems 2 (02), p175-p199.

[2] Moto Kawakane (2015). Fusosha "The impact of the drone", p41-p44

[3] TechClunch:"Drone + X" http://techcrunch.com/2015/09/13/drones-plus-x/( 参照日: 2016 年 1 月 17 日)

[4] Relevant government ministries and agencies contact conference on the Prime Minister's Office a small unmanned aircraft https://www.kantei.go.jp/jp/singi/kogatamujinki/ （accessed on Jan 1st, 2016)

[5] Richard Witteru, Yoko Akane (translation) (2015). Bungei "The Birth of the unmanned drone assassination machine", p106-p110

[6] Moto Kawakane (2015). Fusosha "The impact of the drone", p112-p117

[7] Yuji Tohei, SamuSawa Akira (1988) Japan patent number:.. KOKOKU 06-6199.

[8] Kobayashi AkiraRin (2015). Asahi Shimbun published "The impact of the drone business", p37

[9] Takao Takahashi (2015). Hidekazu Let's make the system "drone! Fly it! "

[10] Philip Kotler, Kevin Lane Keller (2014). Maruzen "Kotler \& Keller Marketing Management 12th edition"

[11] Umezawa S. (2013). Same language museum publication "consumer needs Handbook", p33

[12] Ministry of Economy, Trade and Industry, "Market trend of unmanned aircraft"

[13] https://www.kantei.go.jp/jp/singi/kogatamujinki/dai1/siryou3.pdf (accessed on Jan 1st, 2016)

[14] DRONELIFE.com: "Drone Sales Numbers: Nobody Knows, So We Venture A Guess" http://dronelife.com/2015/04/16/drone-sales-numbers-nobody-knows-so-we-venturea-guess/ (accessed 0n Jan 1st, 2016)

[15] AQU tip Technology Research Institute (2015). "Multirotor, drone applications development, market outlook, survey of market forecasts", p151-p157 
[16] AQU tip Technology Research Institute (2015). "Multirotor, drone applications development, market outlook, survey of market forecasts", p146-p151

[17] AQU tip Technology Research Institute (2015). "Multirotor, drone applications development, market outlook, survey of market forecasts", p157-p160

[18] Roller Mika. (2014). "American trends and legislation concerning domestic flight of the unmanned aircraft," foreign legislation 260, p3-p4

[19] Moto Kawakane (2015). Fusosha "The impact of the drone", p110

[20] The United States Federal Aviation Administration 